\title{
Macular Hole After Pars Plana Vitrectomy for Rhegmatogenous Retinal Detachment
}

\author{
Carlos A. Medina, M.D., Angelica G. Ortiz, M.D., Nidhi Relhan, M.D., William E. Smiddy, \\ M.D., Justin H. Townsend, M.D., and Harry W. Flynn Jr., M.D. \\ Department of Ophthalmology, Bascom Palmer Eye Institute, University of Miami Miller School of \\ Medicine, Miami, Florida
}

\begin{abstract}
Purpose-To report the clinical features, possible associations and treatment outcomes of patients with macular hole after pars plana vitrectomy (single or multiple) for rhegmatogenous retinal detachment.
\end{abstract}

Methods-Retrospective consecutive case series from July 2009 to July 2014.

Results-In the 15 study patients, the average time from retinal detachment surgery to macular hole diagnosis was 119 days (range: 41 - 398 months). Possible associations include epiretinal membrane (73\%, 11/15 patients), macula-off retinal detachment (60\%, 9/15 patients), recurrent retinal detachment (47\%, 7/15 patients) and high myopia (56\%, 5/9 patients). Single surgery was successful in hole closure in 8/15 patients (Group A) while 7/15 patients underwent multiple surgeries (Group B). Macular hole closure was achieved in 7/8 (87.5\%) patients in Group A compared to 4/7 (57.1\%) patients in Group B. Improvement of at least two lines of Snellen's visual acuity was achieved in 4/8 (50.0\%) and 4/7 (57.1\%) patients in Group A and B respectively.

Conclusion-In patients with macular hole formation after pars plana vitrectomy for retinal detachment, possible associations were epiretinal membrane, macula-off retinal detachment, recurrent retinal detachment and high myopia. Even when macular hole closure was achieved, limited visual improvement occurred.

\section{Keywords}

Epiretinal Membrane; Macular Hole; Rhegmatogenous retinal detachment

\section{Background}

Macular hole is a well-known and extensively studied macular disease. Gass was the first to classify and propose tangential vitreo-foveal traction as the underlying cause. ${ }^{1,2}$ More recently, data based on optical coherence tomography (OCT) has supported Gass' original hypothesis attributing macular hole $(\mathrm{MH})$ to vitreo-foveal traction and an OCT based

Corresponding Author: Harry W Flynn Jr. MD., Department of Ophthalmology, Bascom Palmer Eye Institute, University of Miami, Miller School of Medicine, 900 N.W. 17th Street, Miami, Florida 33136, USA, Phone Number +1-305-326-6118, Fax - 305-326-6417, hflynn@med.miami.edu.

Disclosures: None. None of the authors have any proprietary interest. 
classification was developed. ${ }^{3,4}$ This theory has been additionally reinforced by successful treatments of $\mathrm{MH}$ with cortical vitreous peeling. ${ }^{5}$ Thus, both removal of the posterior cortical vitreous and posterior vitreous detachment are thought to relieve these traction forces and be a protective factor to MH development.

The proposed mechanisms seem to be contradicted by a number of patients in which a MH develops after a complete posterior vitreous detachment or even after pars plana vitrectomy (PPV). ${ }^{6,7}$ Brown was the first to describe secondary MHs after retinal detachment (RD) surgery. ${ }^{8}$ These initial reports were associated with scleral buckling surgery and pneumatic retinopexy. ${ }^{8-13}$ Other reports of MHs following pars plana vitrectomy (PPV) followed shortly thereafter. ${ }^{14}$

The incidence of MH following RD repair (pneumatic retinopexy, scleral buckle, vitrectomy or a combination of these) has been reported to be between $0.24 \%$ and $1.9 \% .^{11,15-19}$

Because MH after RD surgery is uncommon, the pathogenesis and outcomes have been mostly described in small retrospective case series. Although, successful closure of the hole has been reported, visual outcomes are usually poor presumably from the preceding RD. ${ }^{19}$

The current study reports a larger consecutive case series of patients developing $\mathrm{MH}$ after RD surgery by PPV.

\section{Methods}

The study was conducted in accordance with the ethical standards established in the 1964 Declaration of Helsinki for research involving humans, and approved by the Institutional Review Board of the University of Miami.

This was a retrospective, single center, multi-surgeon, consecutive case series including all patients who underwent pars plana vitrectomy (single or multiple) for rhegmatogenous retinal detachment from July of 2009 to July of 2014 and subsequently developed a full thickness MH after successful retinal reattachment surgery. Patients who underwent a combined vitrectomy with scleral buckle procedure were also included. Patients with diabetic tractional $\mathrm{RD}$ at presentation or traumatic $\mathrm{RD}$ at presentation or $\mathrm{MH}$ identified before or during the retinal detachment surgery or iatrogenic $\mathrm{MH}$ or $\mathrm{MH}$ detected within 1 month of initial PPV for RD were excluded from the study.

The medical records of these patients were reviewed and patient data including age, refractive error, visual acuity at initial presentation, status of macula, surgical procedure, number of surgeries performed for RD, indication of silicone oil for recurrent $\mathrm{RD}$, surgical procedure for recurrent $\mathrm{RD}$, time interval between initial vitrectomy and $\mathrm{MH}$ formation, visual acuity at time of $\mathrm{MH}$ diagnosis, presence of additional retinal pathology such as proliferative vitreoretinopathy (PVR), surgical procedure performed for $\mathrm{MH}$ surgery (internal limiting membrane [ILM] peeling, $\mathrm{C}_{3} \mathrm{~F}_{8}$ or silicone oil injection), visual acuity at final follow-up, status of $\mathrm{MH}$ at final visit were recorded. 


\section{Results}

Fifteen patients met the study criteria. Eight female and 7 male patients with the average age of 64 years (range 50-86) were included in the study. The refractive error or axial length was known for 9 of 15 eyes. High myopia (refractive error of more than 6 diopters or an axial length of $>26.5 \mathrm{~mm}$ ) was noted in 5/9 (56\%) patients. In the current study, epiretinal membrane (ERM) (73\%, 11/15 patients), macula-off RD (60\%, 9/15 patients), recurrent RD $(60 \%, 9 / 15$ patients) and high myopia $(56 \%, 5 / 9$ patients) were noted.

For MH, single surgery was successful in 8/15 patients (Group A) while 7/15 patients underwent multiple surgeries (Group B). History, clinical presentation and initial surgical management of patients developing macular hole after retinal detachment surgery are shown in Table 1. All patients underwent PPV for rhegmatogenous RD repair. Nine patients received a simultaneous scleral buckle (60\%). During the initial pars plana vitrectomy surgery performed for retinal detachment, no staining agents were used and no membrane (ERM/ILM) peeling in the macular area was performed. None of the patients with high myopia in the current study had myopic macular retinoschisis. Surgical procedure performed and outcomes (anatomical and visual) of MH after RD surgery are shown in Table 2. The average time from initial RD surgery to MH diagnosis was 93 days in Group A and 149 days in Group B with an average in all 15 eyes of 119 days (range $41-398$ months).

\section{Group A}

Among Group A (eyes undergoing single PPV for RD), 7/8 eyes received long acting gas as a tamponade agent. Silicone oil was used in one patient (patient number 8) as an intraoperative choroidal detachment was noted. This patient had presented with macula-off $\mathrm{RD}$ at presentation and developed a macular hole while silicone oil was in the eye 180 days after initial PPV. Among these 8 patients, ERM and ILM was noted in 5 and 6 patients and membrane peeling was performed subsequently during MH surgery.

\section{Group B}

Among group B (eyes undergoing multiple PPV for RD), 71.4\% (5/7) patients presented with a simultaneous recurrent RD and MH (patients 11-15). PVR was noted in 57.1\% (4/7) patients (patient number 12, 13, 14, 15) and underwent silicone oil injection because of the simultaneous retinal detachment. One patient (patient number 11) did not receive silicone oil at the time of MH surgery as retina was attached and stable. Another patient (patient number 9) developed a MH while silicone oil was in the eye after first PPV for RD and underwent silicone oil removal and ILM peeling for MH. Among 7 patients in Group B, ERM and ILM was noted in 6 and 4 patients and membrane peeling was performed during MH surgery.

MH closure was accomplished in 11/15 (73\%) eyes at last follow up (average 302 days, range 18 days to 3 years). $\mathrm{MH}$ closure was achieved in $7 / 8$ (87.5\%) patients in group A while 4/7 (57.1\%) patients in group B. No patients had more than one MH surgery. Of the 11 eyes with macular hole closure, 20/200 or better was achieved in 8 eyes but only 5 eyes achieved 20/80 or better. Mean visual acuity at time of diagnosis of MH was $1.13 \pm 0.5$ (approximately 200/300, range 20/60 to 6/200) in group A and $1.74 \pm 0.7$ (approximately 
$20 / 1000$, range $20 / 100$ to hand motions) in group B respectively. Mean visual acuity at final follow-up was $0.80 \pm 0.5$ (approximately $20 / 120$, range 20/60 to 20/400) and $1.50 \pm 1.2$ (range 20/30 to hand motions) in group A and group B respectively. Improvement of at least two lines of Snellen's visual acuity was noted in 4/8 (50.0\%) patients and 4/7 (57.1\%) patients in group A and group B respectively. No improvement or worsening of visual acuity was noted in $7 / 15(46.7 \%)$ patients.

In the current study, none of the patients in Group A had proliferative vitreoretinopathy (PVR) at presentation while 4/7 patients in Group B had PVR. Because of PVR, these 4 cases in Group B underwent silicone oil injection along with ILM peeling during MH surgery. Mean visual acuity improved in Group B after MH surgery but since the number of patients were small, no statistically significant conclusions can be made. Two of the 4 patients with PVR did not achieve MH closure at the last follow-up.

Visual acuities among various subgroups (high myopic versus non-high myopic patients, macula-on RD versus macula-off $\mathrm{RD}$ at the time of diagnosis of $\mathrm{MH}$, scleral buckling versus no scleral buckling during initial pars plana vitrectomy) are shown in Table 3. Because the number of patients in these subgroups was small, no statistically significant conclusions can be made.

\section{Discussion}

The current study reports a consecutive case series of patients with macular hole after pars plana vitrectomy performed for retinal detachment (single or multiple surgeries). These macular holes appear to be different from idiopathic macular holes in terms of etiology, as well as visual and anatomical outcomes. The study reports possible associations (high myopia, macula off retinal detachment, recurrent retinal detachment, presence of epiretinal membrane) and visual acuity and anatomic outcomes in these patients.

The current retrospective analysis included 15 patients with MH formation following PPV for rhegmatogenous RD. The prevalence for MH following RD ranges from $0.24-1.9 \% .^{15}, 16$ This includes cases of scleral buckle and pneumatic retinopexy procedures for retinal reattachment (Table 4). ${ }^{15-25}$ Clinical characteristics and outcomes from the current study were compared with published data. In the current study, $67 \%$ of patients were younger than 65 years of age. This is similar to published data, were $82 \%$ of patients were younger than 65 years of age. Also similar to published data was the presence of a macula off RD at presentation (73\% vs. $60 \%$ ) and the presence of ERM (69\% vs. $73 \%$ ). The percentage of MH closure as lower in the current study (73\% vs. $92 \%)$. This might be due to the fact that none of the patients in the current study underwent more than one procedure for $\mathrm{MH}$ repair because of the guarded visual prognosis. The current study also found a higher rate of recurrent RD compared to the published literature (60\% vs. 21\%) (Table 5).

In the current study, macula-off RD and high myopia although seen in 60\% and 56\% patients respectively, did not show any statistically significant effect on the visual and anatomical outcomes. Membrane peeling was not performed in the initial PPV for RD. Although a clinical posterior vitreous detachment was noted in $60 \%$ of patients, no vitreous 
staining agents used during initial $\mathrm{RD}$ repair. The risk of residual cortical vitreous with subsequent contraction or absence of a complete posterior vitreous detachment secondary to vitreoschisis remains a possibility. Furthermore contraction of residual vitreous, ERM formation, and proliferative vitreous retinopathy may all have contributed to the residual tractional forces following PPV for RD repair that may have been responsible for $\mathrm{MH}$ formation in some of the cases (Figure 1).

Cystoid macular edema (CME) has been postulated as a mechanism for MH formation in the absence of tangential traction. MH in patients without visible vitreofoveal traction or epiretinal membranes by OCT indicate that non-tractional factors may be contributing to hole formation. There was absence of ERM on OCT in 4 patients (Patient number 3, 5, 6, 10). OCT images of two such patients from current study are shown who developed macular hole despite the absence of visible traction (Patients number 5 \& 6 - Figure 1B \& 1C). We did not measure the size of macular hole in these patients because the color images and OCT images were not taken in a standardized prospective protocol. Instead, multiple cameras (Topcon, Optos, and Heidelberg) were used in imaging these patients.

Patients with prior successful MH surgery have been found be at greater risk for hole reopening from cystoid macular edema following cataract surgery. ${ }^{26}$ Anti-inflammatory treatment with for resolution of the cystoid changes in patients with macular hole without vitreo-foveal traction has been successful in closing macular holes. ${ }^{27}$

PVR at the time of MH diagnosis (4/7 patients in current study), was associated with limited visual improvement. Mean visual acuity in these 4 patients were generally poor (20/100, 20/150, HM, HM) and 2/4 had persistent MH. Overall, MH closure occurred in 73\% (11/15) patients. Current series had few limitations in being a retrospective study, small number of patients and cases operated by multiple surgeons. Despite various limitations, the current study showed that MH formation after PPV for RD may be associated with ERM (73\%, $11 / 15$ patients), macula-off RD (60\%, 9/15 patients), recurrent RD (60\%, 9/15 patients) and high myopia (56\%, 5/9 patients). MH closure was achieved in the majority of patients (73\%, 11/15 patients) but with limited visual improvement. The possible reasons for limited recovery of vision in the group of eyes in which the macular hole was closed include progressive cataract, retained silicone oil in the eye or myopic macular degeneration. Because this is a retrospective study, information on the exact reasons of reduced visual acuity in these patients was not always recorded in the medical records. Among patients with persistent MH at final follow-up, two patients (patient number - 12 and 13) had very poor final visual acuity (hand motions) and both these patients had multiple procedures and had retained silicone oil at last follow-up.

\section{Acknowledgments}

Funding Support - We acknowledge support from the National Institute of Health (NIH) Center Core Grant P30EY014801 (Bethesda, Maryland), Research to Prevent Blindness Unrestricted Grant (New York, New York), and the Department of Defense (DOD Grant \#W81XWH-09-1-0675) (Washington, DC). 


\section{References}

1. Gass JD. Reappraisal of biomicroscopic classification of stages of development of a macular hole. Am J Ophthalmol. 1995 Jun; 119(6):752-9. [PubMed: 7785690]

2. Gass JD. Idiopathic senile macular hole. Its early stages and pathogenesis. Arch Ophthalmol. 1988 May; 106(5):629-39. [PubMed: 3358729]

3. Gaudric A, Haouchine B, Massin P, et al. Macular hole formation: new data provided by optical coherence tomography. Arch Ophthalmol. 1999 Jun; 117(6):744-51. [PubMed: 10369584]

4. Duker JS, Kaiser PK, Binder S, et al. The International Vitreomacular Traction Study Group classification of vitreomacular adhesion, traction, and macular hole. Ophthalmology. 2013 Dec; 120(12):2611-9. [PubMed: 24053995]

5. Kelly NE, Wendel RT. Vitreous surgery for idiopathic macular holes. Results of a pilot study. Arch Ophthalmol. 1991 May; 109(5):654-9. [PubMed: 2025167]

6. Gordon LW, Glaser BM, Ie D, et al. Full-thickness macular hole formation in eyes with a preexisting complete posterior vitreous detachment. Ophthalmology. 1995 Nov; 102(11):1702-5. [PubMed: 9098265]

7. Smiddy WE. Macular hole formation without vitreofoveal traction. Arch Ophthalmol. 2008 May; 126(5):737-8. [PubMed: 18474794]

8. Brown GC. Macular hole following rhegmatogenous retinal detachment repair. Arch Ophthalmol. 1988 Jun; 106(6):765-6. [PubMed: 3370002]

9. Benson WE, Cruickshanks KC, Fong DS, et al. Surgical management of macular holes: a report by the American Academy of Ophthalmology. Ophthalmology. 2001 Jul; 108(7):1328-35. [PubMed: 11425696]

10. Boscia F, Recchimurzo N, Cardascia N, et al. Macular hole following conventional repair of bullous retinal detachment using air injection (D-ACE procedure). Eur J Ophthalmol. 2004 NovDec;14(6):572-4. [PubMed: 15638111]

11. Moshfeghi AA, Salam GA, Deramo VA, et al. Management of macular holes that develop after retinal detachment repair. Am J Ophthalmol. 2003 Nov; 136(5):895-9. [PubMed: 14597042]

12. Avins LR, Krummenacher TR. Macular holes after pneumatic retinopexy. Case reports. Arch Ophthalmol. 1988 Jun; 106(6):724-5. [PubMed: 3369990]

13. Hejny C, Han DP. Vitrectomy for macular hole after pneumatic retinopexy. Retina. 1997; 17(4): 356-7. [PubMed: 9279957]

14. Smiddy WE. Atypical presentations of macular holes. Arch Ophthalmol. 1993 May; 111(5):62631. [PubMed: 8489442]

15. Lee SH, Park KH, Kim JH, et al. Secondary macular hole formation after vitrectomy. Retina. 2010 Jul-Aug;30(7):1072-7. [PubMed: 20168267]

16. Schlenker MB, Lam WC, Devenyi RG, Kertes PJ. Understanding macular holes that develop after repair of retinal detachment. Can J Ophthalmol. 2012 Oct; 47(5):435-41. [PubMed: 23036545]

17. Benzerroug M, Genevois O, Siahmed K, et al. Results of surgery on macular holes that develop after rhegmatogenous retinal detachment. Br J Ophthalmol. 2008 Feb; 92(2):217-9. [PubMed: 18227202]

18. Shibata M, Oshitari T, Kajita F, et al. Development of macular holes after rhegmatogenous retinal detachment repair in Japanese patients. J Ophthalmol. 2012; 2012:740591. [PubMed: 22315662]

19. Garcia-Arumi J, Boixadera A, Martinez-Castillo V, et al. Macular holes after rhegmatogenous retinal detachment repair: surgical management and functional outcome. Retina. 2011 Oct; 31(9): 1777-82. [PubMed: 21606891]

20. Kimura H, Kuroda S, Nagata M. Macular hole formation in postvitrectomized eyes. Retina. 2005 Jun; 25(4):521-3. [PubMed: 15933604]

21. Tsilimbaris MK, Gotzaridis S, Charisis SK, et al. Spontaneous closure of macular holes developed after pars plana vitrectomy. Semin Ophthalmol. 2007 Jan-Mar;22(1):39-42. [PubMed: 17366118]

22. Sheth HG, Bainbridge J. Development of full-thickness macular hole despite previous posterior vitreous detachment and vitrectomy for retinal detachment: two cases. Eur J Ophthalmol. 2008 Nov-Dec;18(6):1025-7. [PubMed: 18988183] 
23. Kumagai K, Ogino N, Furukawa M, et al. Surgical outcomes for patients who develop macular holes after pars plana vitrectomy. Am J Ophthalmol. 2008 Jun; 145(6):1077-80. [PubMed: 18378210]

24. Rahman W, Georgalas I, da Cruz L. Macular hole formation after vitrectomy for retinal detachment. Acta Ophthalmol. 2010 Jun; 88(4):e147-8. [PubMed: 19764913]

25. Fabian ID, Moisseiev E, Moisseiev J, et al. Macular hole after vitrectomy for primary rhegmatogenous retinal detachment. Retina. 2012 Mar; 32(3):511-9. [PubMed: 21799463]

26. Bhatnagar P, Kaiser PK, Smith SD, et al. Reopening of previously closed macular holes after cataract extraction. Am J Ophthalmol. 2007 Aug; 144(2):252-9. [PubMed: 17543876]

27. Kurz PA, Kurz DE. Macular hole closure and visual improvement with topical nonsteroidal treatment. Arch Ophthalmol. 2009 Dec; 127(12):1687-8. [PubMed: 20008730] 


\section{Summary Statement}

In this retrospective case series, 15 patients developed full thickness macular hole following retinal detachment repair using vitrectomy. Hole closure was achieved in the majority of patients surgically but closure was associated with only modest visual improvement. 

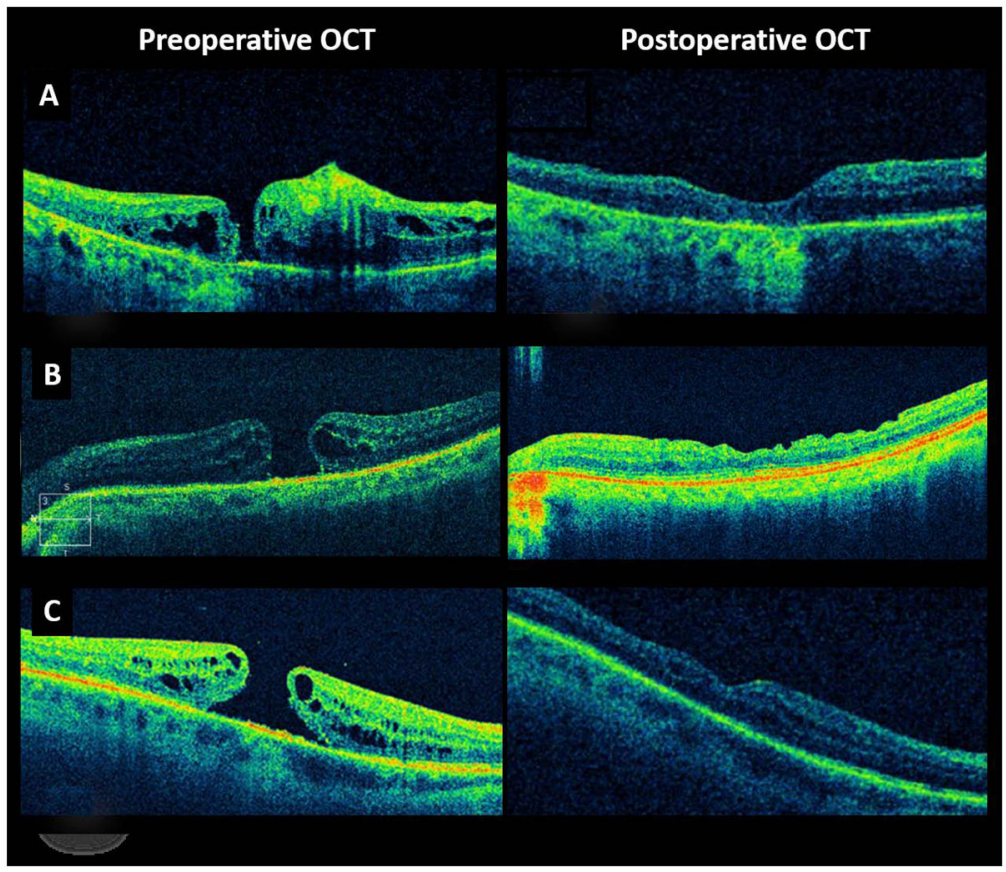

Figure 1.

OCT images (preoperative and postoperative) of patients from current study (number 4, 5 and 6) developing macular hole after pars plana vitrectomy for retinal detachment. (A) Preoperative OCT of patient number 4 shows full thickness macular hole with visual acuity 20/400. Postoperative OCT (4 months after macular hole surgery) shows closure of macular hole, foveal thinning and loss of IS-OS layer with 20/150 visual acuity. (B) Preoperative OCT of patient number 5 shows full thickness macular hole and 20/400 visual acuity. Postoperative OCT ( 6 weeks after macular hole surgery) shows macular hole closure and foveal thinning with 20/200 visual acuity. (C) Preoperative OCT of patient number 6 shows full thickness macular hole and visual acuity 20/400. Postoperative OCT (4 weeks after macular hole surgery) macular hole closure and cystic changes at fovea with 20/60 visual acuity. 


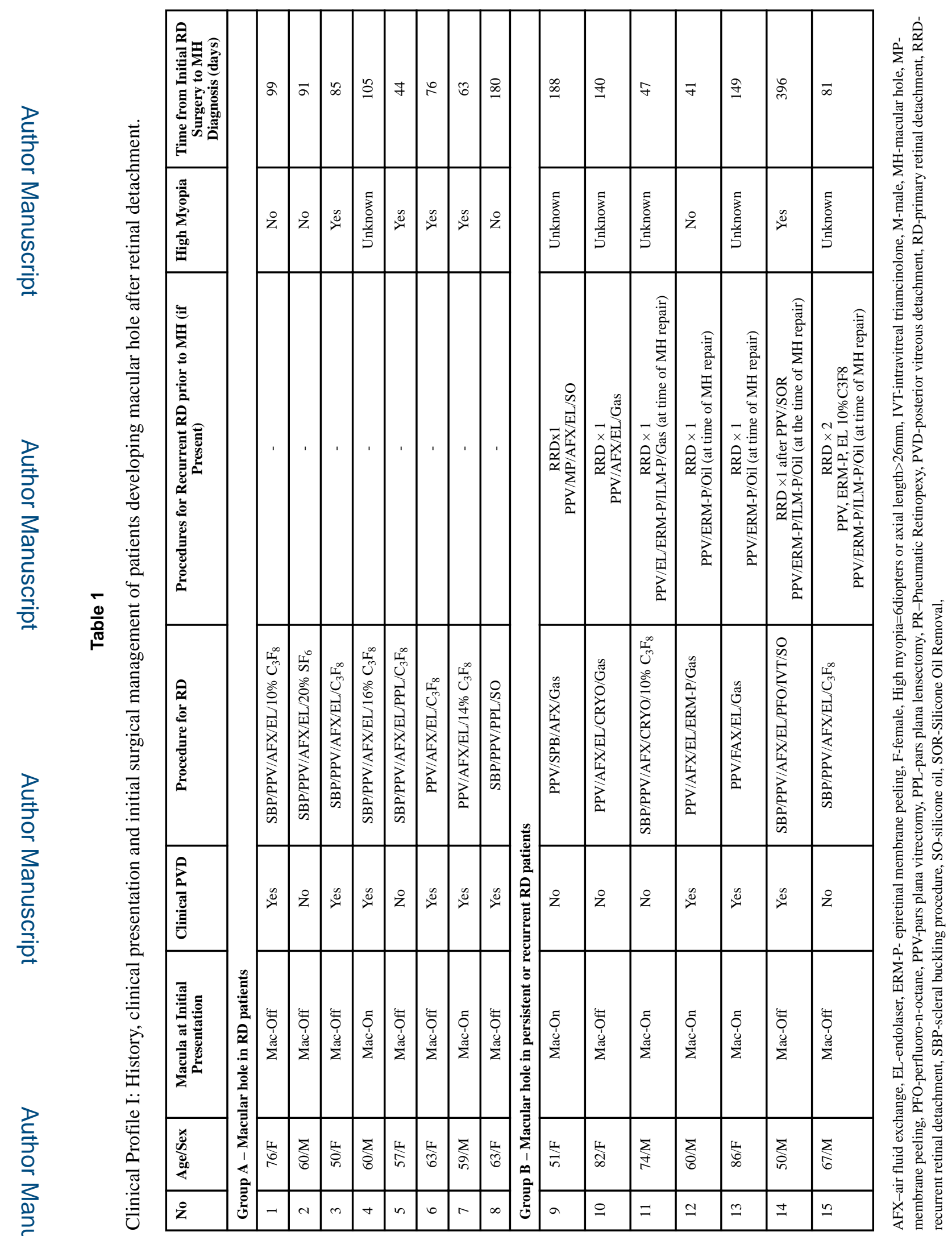

Retina. Author manuscript; available in PMC 2018 June 01. 


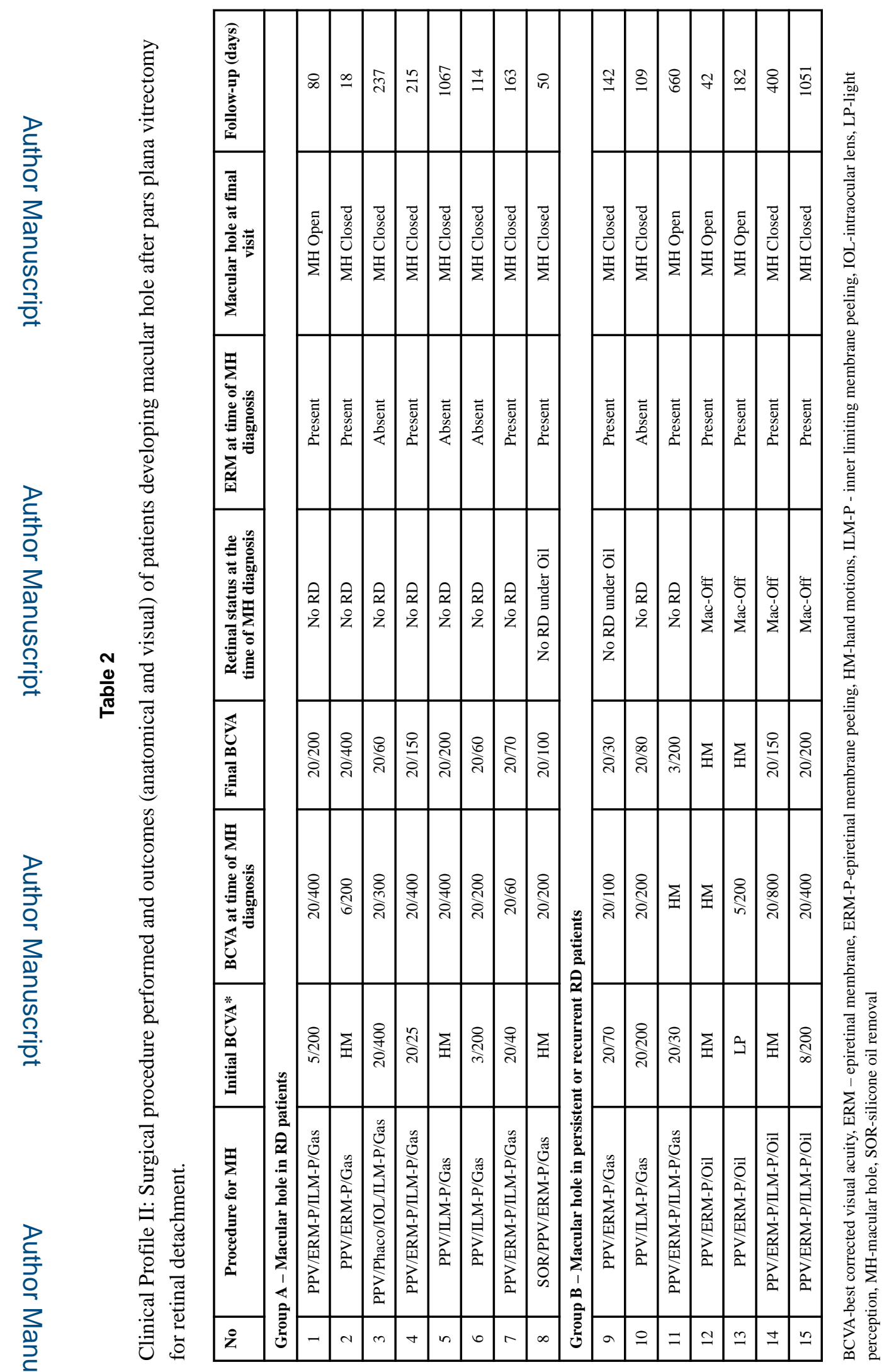

Retina. Author manuscript; available in PMC 2018 June 01. 


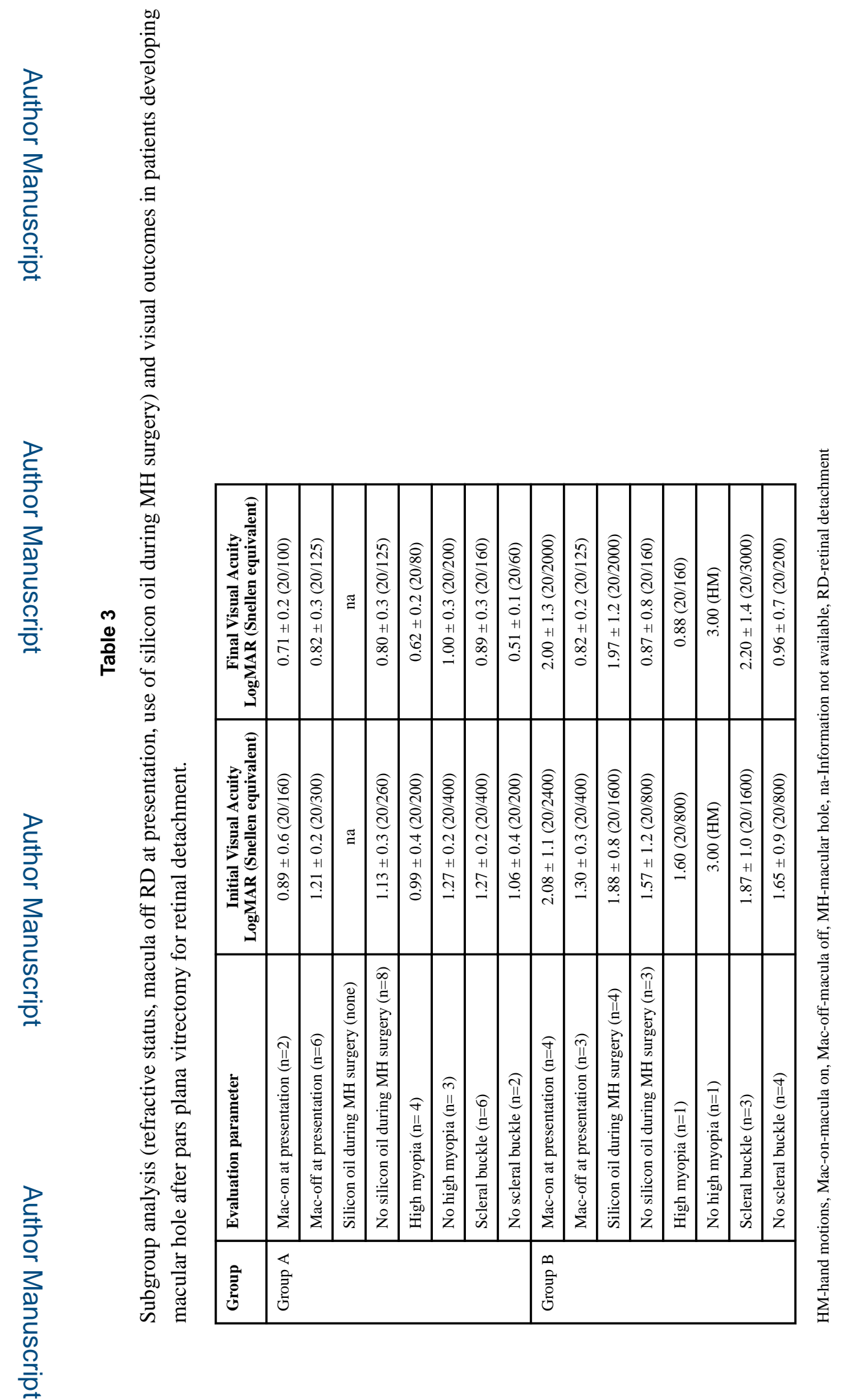

Retina. Author manuscript; available in PMC 2018 June 01. 


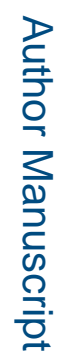

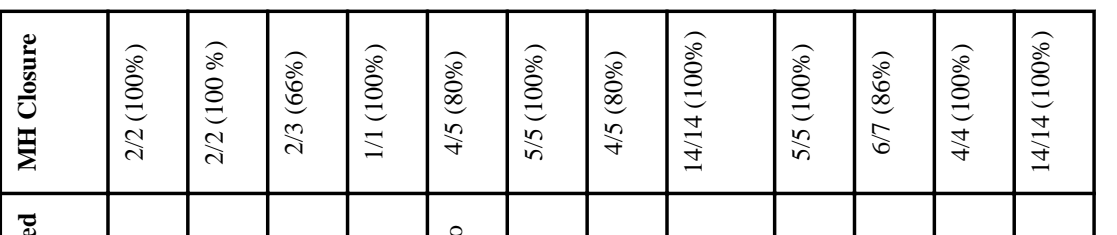

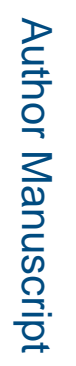

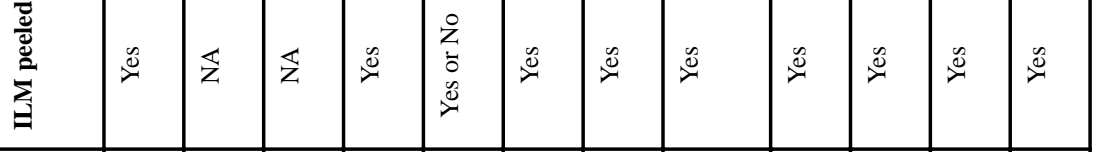

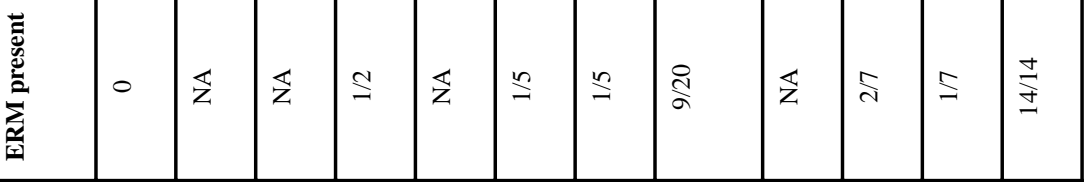

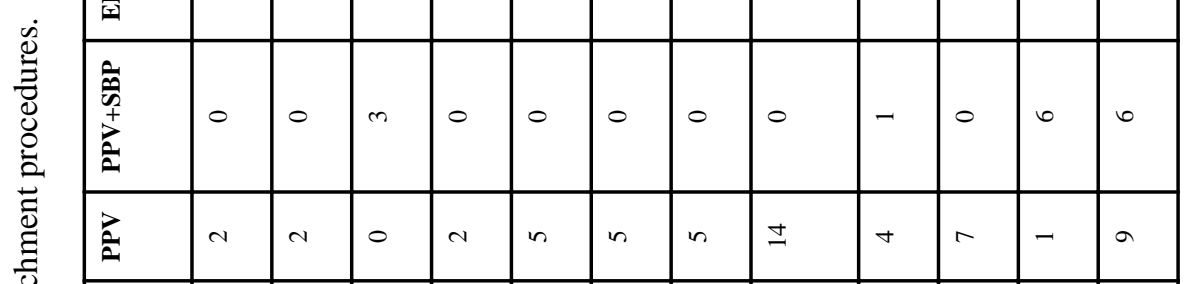

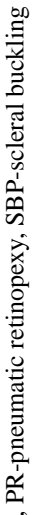

로을

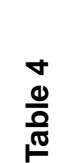

\begin{tabular}{|c|c|c|c|c|c|c|c|c|c|c|c|c|}
\hline 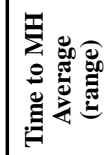 & 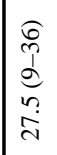 & $\stackrel{2}{\stackrel{2}{2}}$ & $\underset{r}{\stackrel{\infty}{I}}$ & 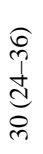 & $\mathbb{z}$ & $\begin{array}{l}a \\
o \\
b \\
b \\
e \\
\infty \\
i j \\
0\end{array}$ & 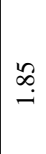 & $\begin{array}{l}\widehat{\sigma} \\
0 \\
n \\
\hat{0} \\
0 \\
0\end{array}$ & 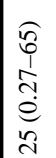 & 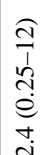 & 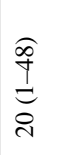 & 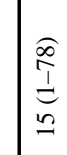 \\
\hline
\end{tabular}

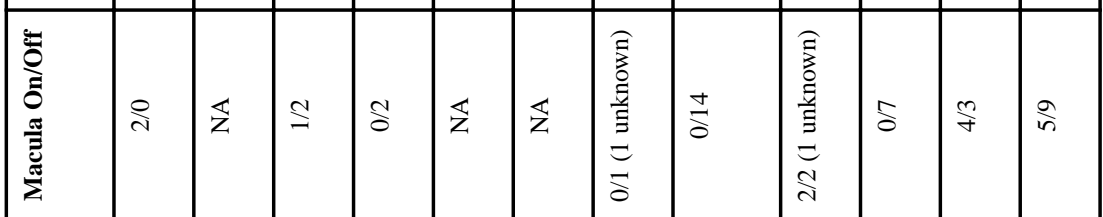

모

\begin{tabular}{|c|c|c|c|c|c|c|c|c|c|c|c|c|}
\hline 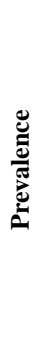 & $\overleftrightarrow{z}$ & 艺 & 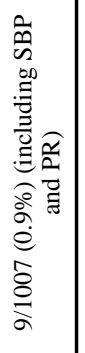 & $\mathbb{z}$ & 忞 & 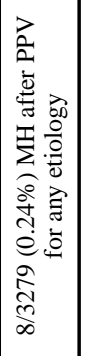 & $\overleftrightarrow{z}$ & 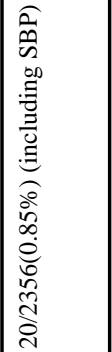 & 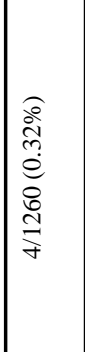 & 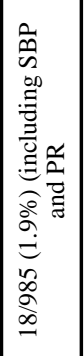 & 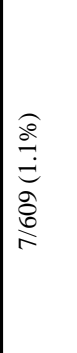 & $\mathbb{z}$ \\
\hline $\begin{array}{l}\ddot{n} \\
\ddot{n} \\
\ddot{n} \\
v\end{array}$ & $\ddot{ت}$ & $\begin{array}{l}\ddot{i} \\
\ddot{v}\end{array}$ & $\ddot{m}$ & $\ddot{\sigma}$ & $\overleftrightarrow{z}$ & $\begin{array}{l}N \\
\ddot{n}\end{array}$ & $\overrightarrow{\ddot{q}}$ & $\ddot{\ddot{g}}$ & $\begin{array}{l}0 \\
i n\end{array}$ & $\ddot{6}$ & $\ddot{n}$ & $\begin{array}{l}\stackrel{+}{0} \\
\ddot{\theta}\end{array}$ \\
\hline 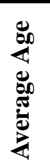 & $\begin{array}{l}\frac{1}{2} \\
\frac{1}{0} \\
0 \\
0 \\
0\end{array}$ & $\begin{array}{l}a \\
b \\
1 \\
\infty \\
c \\
i n \\
i n\end{array}$ & 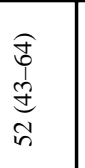 & $\begin{array}{l}\widehat{\sigma} \\
1 \\
d=0 \\
0 \\
0\end{array}$ & $\begin{array}{l}\frac{1}{3} \\
z \\
5\end{array}$ & $\begin{array}{l}\frac{\infty}{0} \\
\frac{1}{d} \\
d \\
i n\end{array}$ & $\begin{array}{l}\widehat{\hat{~}} \\
b \\
b \\
0 \\
\dot{0} \\
i \\
i n\end{array}$ & 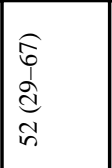 & 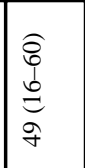 & $\begin{array}{l}\text { T̂́ } \\
0 \\
0 \\
7\end{array}$ & 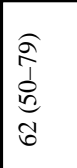 & 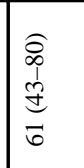 \\
\hline$\stackrel{\ddot{n}}{\ddot{\Sigma}}$ & $\ddot{\ddot{v}}$ & $\ddot{0}$ & $\ddot{\circ}$ & $\ddot{\sim}$ & $\stackrel{N}{\ddot{r}}$ & $\stackrel{+}{-}$ & $\begin{array}{l}\circ \\
\ddot{n}\end{array}$ & $\begin{array}{l}\infty \\
\ddot{0}\end{array}$ & $\begin{array}{l}N \\
\ddot{r}\end{array}$ & $\ddot{q}$ & $\stackrel{+}{\ddot{\sim}}$ & $\stackrel{0}{\infty}$ \\
\hline 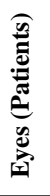 & $\underset{\mathrm{d}}{\mathrm{d}}$ & $\underset{\mathrm{N}}{\widehat{d}}$ & बิ & $\underset{\mathrm{d}}{\mathrm{d}}$ & $\begin{array}{l}n \\
i n\end{array}$ & $\frac{\hat{n}}{n}$ & $\begin{array}{l}n \\
n \\
n\end{array}$ & 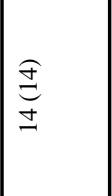 & $\sqrt{n}$ & $\underset{r}{E}$ & $\frac{0}{1}$ & $\begin{array}{l} \pm \\
\pm\end{array}$ \\
\hline$\stackrel{\check{\Xi}}{\Xi}$ & 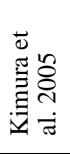 & 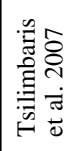 & 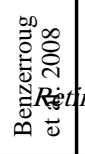 & 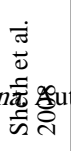 & 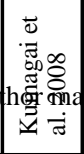 & 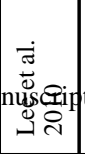 & 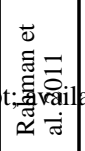 & 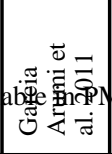 & 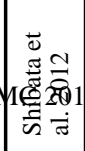 & 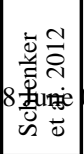 & 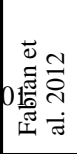 & 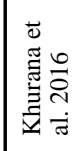 \\
\hline
\end{tabular}

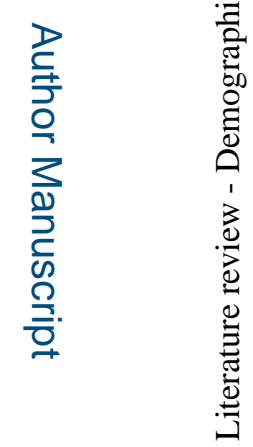


